\title{
Zinc status in infants and children with cholestatic liver diseases and its effect on growth
}

\author{
Nehal Abdelhamid ${ }^{1 *} \mathbb{D}$, Aliaa Wahby ${ }^{2}$ and Manal E. Kandil ${ }^{1}$
}

\begin{abstract}
Objectives and study: Zinc deficiency in children with cholestatic liver diseases could affect growth and immunity. Zinc supplementation is one of the strategies to prevent the consequences of zinc deficiency in children. We aimed to study the effect of zinc supplementation on the growth of these children.

Methods: Fifty-five infants and children (0.5-10 years) with cholestatic liver diseases enrolled from pediatrics hepatology clinic, Cairo University Hospital: 27 post-Kasai, 7 with Alagille syndrome, and 21 with progressive familial intrahepatic cholestasis. Serum zinc, insulin-like growth factor 1 (IGF-1), and anthropometric measurements are measured at enrollment and 4 months after zinc supplementation and in 30 healthy children with matched age and sex. Serum zinc was measured by atomic absorption spectrometry.

Results: The mean initial serum zinc ( \pm SD) in cholestatic and healthy control group was $1251 \pm 558$ and $1461 \pm$ $506 \mathrm{ug} / \mathrm{l}$, respectively $(P>0.05)$. Meanwhile, serum IGF1 median (IQR; range) in patients and control was $54(118 ; 10$ : $780) \mathrm{ng} / \mathrm{ml}$ and $250(387 ; 55: 635) \mathrm{ng} / \mathrm{ml}$, respectively $(p<0.001)$. No statistically significant difference was found between post-Kasai patients and other cholestatic diseases. Children supplemented with zinc had their serum zinc $2223 \pm 1042 \mathrm{ug} / \mathrm{I}(P<0.001)$ and IGF1 median (IQR; range) $346(370 ; 50: 825) \mathrm{ng} / \mathrm{ml}(P<0.001)$. In addition, among anthropometric variables, height (length) $Z$-score and percentile were significantly improved $(P<0.01$ ).

Conclusion: As compared with the baseline, zinc supplementation had significantly elevated serum zinc levels and IGF1 and improved growth in children with cholestatic liver diseases. Thus, zinc supplementation is beneficial for growth in children with cholestatic liver diseases.
\end{abstract}

Keywords: Zinc, Children, Cholestasis, Liver diseases

\section{Background}

Zinc is an essential trace element required for normal growth and development. It is the second most prevalent trace element in the human body and has important antioxidant, anti-inflammatory, and anti-apoptotic effects. It is required for cell growth and maturation. Daily zinc consumption for healthy children between 1 and 18 years old varies from 3-11 mg/day. Zinc restores mucosal barrier integrity and enterocyte brush-border enzyme activity; it promotes the production of antibodies and circulating lymphocytes against intestinal

\footnotetext{
* Correspondence: ibra_n2005@yahoo.com; http://www.nrc.sci.eg ${ }^{1}$ Department of Pediatrics, National Research Center, El Buhouth St, Dokki, Cairo 12311, Egypt

Full list of author information is available at the end of the article
}

pathogens and has a direct effect on ion channels, acting as a potassium channel blocker of adenosine 3-5-cyclic monophosphate-mediated chlorine secretion (Wanzira \& Lazzerini, 2016). The whole blood, plasma, and urine zinc levels decrease in severe zinc deficiency (Tako, 2019). Its deficiency causes growth affection in children and adolescents (Umusig-Quitain \& Gregorio, 2010). In addition, it can cause skin rash, diarrhea, and immunodeficiency (Pereira et al., 2011).

Cholestasis is a common presentation of childhood liver diseases. Children with cholestatic liver disease had lower serum zinc levels compared with the healthy children. The reason of zinc deficiency in liver diseases patients is likely to be multifactorial, including altered intestinal transport, reduced dietary intake, and high 
urinary losses. Moreover, induction of hepatic metallothionein results in zinc sequestration. Zinc deficiency and high urinary zinc losses were reported in children with liver failure before transplant. As the state of liver disease worsened, the zinc levels dropped. Normalization of zinc status without supplementation followed liver transplantation (Narkewicz et al., 1999; Krebs, 2000).

Insulin growth factor 1 (IGF-1) is a small molecular weight hormone. It is formed of 70 amino acids, and unlike other peptides, $99 \%$ of IGF-1 is protein bound. Since the biochemical structure of IGF-1 is similar to that of the insulin receptor, the free IGF-1 possesses a high affinity to bind with IGF-1 receptor compared to that of insulin receptor, inducing cell proliferation and inhibiting apoptosis (Abdel-Wahab et al., 2015).

Approximately $75 \%$ of circulating IGF-1 synthesized by the liver is believed to perform an endocrine function as it is typically acting remotely (Ohlsson et al., 2009). Chronic liver disease is associated with growth hormone resistance, which is characterized by high circulating growth hormone and low IGF-1 concentrations. Standard growth hormone replacement has no effect on serum IGF-1 in pediatric liver disease (Holt et al., 1999).

Zinc deficiency decreases circulating insulin-like growth factor 1 concentration apart of total energy intake (Prasad, 2013). A low serum IGF-1 level leads to several metabolic changes caused by reduced peripheral glucose and lipid uptake, increased hepatic glucose production, elevated stored triglyceride hydrolysis, and subsequently increased circulating glucose and free fatty acid levels (Bonefeld \& Møller, 2011). The role of zinc in the development and growth of children suffering chronic liver disease is poorly defined (Lindenmayer et al., 2013). Well-controlled trials of zinc supplementation have not been conducted in either adults or children, but the potential benefit of further studies appears indicated (Mohammad et al., 2012).

Thus, we aimed to study the effect of zinc supplementation on the growth of children suffering from cholestatic liver diseases and to examine the interactions between zinc and insulin growth factor 1 .

\section{Patients and methods}

\section{Study design}

The present study is a cohort study, which was carried out at the Pediatric Hepatology Department, New Children Hospital, Cairo University, Egypt, from the beginning of June 2016 to the end of June 2017. All patients were enrolled in the study after an informed consent obtained from parent/guardian. The Research Ethics Committee of the Pediatric Department, Faculty of Medicine, Cairo University, and National Research Center, Egypt (Registration number 15152), approved the study. The research was carried out in accordance with the Declaration of Helsinki.

The study enrolled 55 infant and children (0.5-10 years) of both sex, with chronic cholestatic liver disease. Full demographic and clinical characteristics were reported. Anthropometric measurements included weight in kilograms, weight percentile, weight $Z$-score, height (length) in centimeters, height (length) percentile, height (length) $Z$-score, tricuspid skin fold thickness (TSF) in millimeters, TSF percentile, TSF Z-score, mid upper arm circumference (MUAC) in centimeter, MUAC percentile, and MUAC $Z$-score. Weight was measured on a digital infant balance scale with a $10-\mathrm{g}$ precision and length with a 1-mm precision with the use of a rigid length board with an adjustable foot piece for children less than 3 years, and body height was measured without shoes using Holtain stadiometer for children more than 3 years and approximated to the nearest $0.1 \mathrm{~cm}$. They were plotted on the Egyptian growth curves (Ghali et al., 2008). The skin fold thickness measurements were taken at three sites, namely triceps, subscapular, and supra iliac, using Slim Guide Plastic skin fold caliper. They were recorded as the mean of three accepted consecutive readings (Paul et al., 1998). Assessment of skin manifestations of zinc deficiency and complications such as presence of recurrent infections was recorded.

Patients were subjected to the following laboratory investigations: complete blood count $(\mathrm{CBC})$, liver function tests, total and direct bilirubin, aminotransferases, alkaline phosphatase (ALK), glutamyltranspeptidase (GGT), albumin, and prothrombin time (PT).

Serum zinc level was measured by atomic absorption spectrometry.

Detection and quantitation of IGF-1 were performed using the human insulin-like growth factor 1 (IGF-1) ELISA kit (INNOVA Biotech Co. Ltd., China) according to the protocol included with the kit.

Thirty infants and children apparently healthy with matched age and sex were selected from outpatient clinic (Centre of Scientific Excellence, NRC) as control group and were tested for serum zinc level and insulinlike growth factor 1.

Zinc sulfate supplement $(1 \mathrm{mg} / \mathrm{kg})$ was given to all patients and included those reported to have low serum zinc level. They were followed up by re-evaluation clinically (anthropometric measurements) and laboratory by serum zinc level and IGF-1 status at the end of 4 months.

\section{Statistical methods}

Data were statistically described in terms of mean \pm standard deviation $( \pm \mathrm{SD})$, median, range, and IQ range or frequencies (number of cases) and percentages when appropriate. Comparison of numerical variables between 
the study groups was done using Student's $t$ test for independent samples in comparing normally distributed data and the Mann Whitney $U$ test for independent samples for comparing not-normal data. For comparing categorical data, chi-square $\left(\chi^{2}\right)$ test was performed. $P$ values less than 0.05 was considered statistically significant. Statistical analyses were performed using SPSS software (SPSS, version 23.0; SPSS, Chicago, IL, USA).

\section{Results}

The study enrolled 55 infants and children with chronic cholestatic liver disease; demographic characteristics and laboratory data are shown in Table 1. The main underlying etiology of cholestasis in the studied group was post-Kasai in $49 \%$, Alagille syndrome in $12.7 \%$, progressive familial intrahepatic cholestasis type I and type II in $25.3 \%$, and cholestasis with high GGT in $13 \%$.

Skin manifestations of zinc deficiency were reported in $30 \%$ cases (brittle hair in $6(10.9 \%)$, dermatitis in 1 $(1.8 \%)$, and dry skin in $10(18 \%))$, while other general examinations showed rickets in $6(10.9 \%)$, dental caries in $7(12.7 \%)$, and clubbing in $3(5.4 \%)$. History of recurrent infections was recorded in 10 patients $(18 \%)$ and hypogeusia in 2 (3.6\%).

The mean serum zinc level of the entire cholestatic group was lower $1252 \mu \mathrm{g} / \mathrm{l}( \pm \mathrm{SD}=5580.47)$ than the

Table 1 Demographic and laboratory data of the cholestatic patients

\begin{tabular}{ll}
\hline Variables & \\
\hline Sex (male/female) & $32 / 23$ \\
Age (years) (median (IQR), [range]) & $2.2(2.7),[0.5: 10]$ \\
Diagnosis & $27(49 \%)$ \\
$\quad$ Post-Kasai & $28(51 \%)$ \\
$\quad$ Other cholestatic diseases & $1.8(11),[0.2: 31]$ \\
Total serum bilirubin (mg/dl) & \\
(median (IQR), [range]) & $1.4(8.4),[0.00: 21]$ \\
Direct serum bilirubin (mg/dl) & \\
(median (IQR), [range]) & $69(77),[13: 502]$ \\
ALT (u/l) (median (IQR), [range]) & $100(174),[37: 493]$ \\
AST (u/l) (median (IQR), [range]) & $487(446),[104: 1718]$ \\
ALK (u/l) (median (IQR), [range]) & $112(321),[5: 775]$ \\
GGT (u/l) (median (IQR), [range]) & $3.4 \pm 0.9$ \\
Serum albumin (g/dl) (mean \pm SD) & $1.3 \pm 0.7$ \\
INR (mean \pm SD) & $10.8 \pm 1.6$ \\
Hb (g/dl) (mean \pm SD) & $7.4(4.1),[1.9: 70]$ \\
TLC (median (IQR), [range]) & $199(212),[42: 577]$ \\
Platelet median (IQR), [range]) &
\end{tabular}

IQR interquartile range, $S D$ standard deviation, $H b$ hemoglobin, $T L C$ total leucocytic count, ALT alanine transaminase, AST aspartate transaminase, ALK alkaline phosphatase, GGT gamma-glutamyl transferase, INR international normalized ratio control group $1461 \mu \mathrm{g} / \mathrm{l}( \pm \mathrm{SD}=506)$ but not statistically significant $(P>0.05)$.

There was no significant correlation between serum zinc before supplementation and serum alkaline phosphatase as well as hemoglobin. In addition, no significant correlation was found between serum zinc level before supplementation and all anthropometric measurements (MUAC $Z$-score, TSF $Z$-score, weight $Z$ score, height $Z$-score). Meanwhile, significant difference in serum IGF-1 was observed between patients and control groups (Table 2). However, post kasai patients showed no significant difference when compaired to other cholestatic patients (Table 3).

\section{After zinc supplementation}

Following the intake of zinc sulfate $(1 \mathrm{mg} / \mathrm{kg}$ daily) for 4 months, a significant improvement and almost doubling of mean serum $\mathrm{Zn}$ (mean \pm SD) $(2223 \pm 1042 \mu \mathrm{g} / \mathrm{l} ; P=$ $0.001)$ as well as significant increase in serum IGF-1 (median (IQR); range) (346 (370); 50:825) $(P=0.001)$ were observed. Furthermore, among various anthropometric measurements, the height (length) $Z$-score and percentile showed statistically significant improvement as shown in Table 4.

\section{Discussion}

Although failure to thrive (FTT) is associated with different chronic diseases, nutritional supply and absorption were prominent factors associated with FTT. Therefore, intensive nutrition therapy may help with catch-up growth. Zinc after absorption by the small intestine is carried to the liver by portal circulation. Zinc absorption is regulated by matallotheionin that binds both $\mathrm{Cu}$ and $\mathrm{Zn}$ and helps as a $\mathrm{Zn}$ storage protein in the liver (Sandström, 1997). Recently, zinc and the proteins that transfer zinc ion have been implicated in the endoplasmic reticulum stress response. Specifically, the endoplasmic reticulum-specific zinc transporter ZIP7, named the gatekeeper of zinc release from the endoplasmic reticulum into the cytosol, was found to be essential for maintaining endoplasmic reticulum homeostasis in intestinal epithelium cells (Adulcikas et al., 2019).

Zinc deficiency in infants and children has been known to cause malabsorption and loss of appetite (Monge et al., 2019). In addition, it leads to dry skin,

Table 2 Comparison between serum Zn and IGF-1 before treatment in the cholestatic patients and control

\begin{tabular}{llll}
\hline Variables & Patients & Controls & $\begin{array}{l}P \\
\text { value }\end{array}$ \\
\hline Serum Zn (mean \pm SD) $\mu \mathrm{g} / \mathrm{l}$ & $1252 \pm 557$ & $1461 \pm 506$ & $>0.05$ \\
IGF-1 (median (IQR), [range]) & $54(118),[10:$ & $250(387,[55:$ & $0.001^{*}$ \\
$\mathrm{ng} / \mathrm{ml}$ & $780]$ & $635])$ & \\
\hline
\end{tabular}

${ }^{*} P<0.05$ is significant 
Table 3 Comparison between post-Kasai patients and other cholestatic patients before intervention

\begin{tabular}{|c|c|c|c|}
\hline Variables & Cholestasis $(n=28)$ & Post-Kasai $(n=27)$ & $P$ value \\
\hline MUAC Z-score (median (IQR), [range]) & $-1.5(2.2),[-5.8: 0.83]$ & $-1.2(1.7),[-5.9: 0.92]$ & $>0.05$ \\
\hline MUAC percentile (median (IQR), [range]) & $6.5(44),[0.00: 80]$ & $12(38),[0.00: 82]$ & $>0.05$ \\
\hline TSF Z-score (median (IQR), [range]) & $-2.8(1.2),[-7.73:-0.07]$ & $-2.2(2.2),[-7.6: 0.2]$ & $>0.05$ \\
\hline TSF percentile (median (IQR), [range]) & $0.00(1),[0.00: 47]$ & 1 (10), [0.00:58] & $>0.05$ \\
\hline Weight Z-score (median (IQR), [range]) & $-1.5(1.8),[-3.9: 6.3]$ & $-0.6(1.8),[-5.5: 0.9]$ & $>0.05$ \\
\hline Weight percentile (median (IQR), [range]) & $4(21),[0.00: 97]$ & $22.5(41.7),[-2.7: 81]$ & $>0.05$ \\
\hline Height (length) Z-score (median (IQR), [range]) & $-1.8(1.7),[-4.8: 2.4]$ & $-0.9(2.8),[-3.6: 41]$ & $>0.05$ \\
\hline Height (length) percentile (median (IQR), [range]) & $3(11),[0.00: 99]$ & $14.5(44.5),[-0.2: 92]$ & $>0.05$ \\
\hline Serum Zn (mean \pm SD) $\mu \mathrm{g} / \mathrm{l}$ & $1222 \pm 512$ & $1282 \pm 610$ & $>0.05$ \\
\hline IGF-1 (median (IQR), [range]) ng/ml & 46 (81), [10:550] & 57 (369), [18:780] & $>0.05$ \\
\hline
\end{tabular}

${ }^{*} P<0.05$ is significant

delayed healing of wounds, immune dysfunctions, and abnormal neurosensory changes (World Health Organization, 2004). It is important to maintain a consistent supply because zinc is not stored in the body (Sultan et al., 2015). The normal range of serum zinc levels is $700-1200 \mu \mathrm{g} / \mathrm{l}$ (Soldin et al., 1999).

Our study shows lower level of serum $\mathrm{Zn}$ in children with chronic compensated cholestasis than healthy control group. However, it was not statistically significant $(P$ $>0.05)$. Umusig-Quitain and Gregorio (2010) found that children with chronic liver disease, whether in a compensated or decompensated state, had lower $\mathrm{Zn}$ level compared to healthy controls. This finding might be the result of decreased liver albumin, poor food intake or protein restriction, and increased clearance of zinc (Umusig-Quitain \& Gregorio, 2010; Soldin et al., 1999).

Zinc supplementation at doses no higher than $10 \mathrm{mg} /$ day increased the serum zinc concentrations of children and reduced the risk of suffering from zinc deficiency, whereas the effect of zinc administered in fortification trials, although in comparable concentrations as supplemental zinc, had no significant effect on serum zinc levels (Lin \& Huang, 2006). In addition, studies in children with short stature found that $10 \mathrm{mg} /$ day of elemental zinc supplementation improved growth (Petry et al., 2016), mid upper arm circumference (Ninh et al., 1996), and biochemical markers of bone metabolism (Imamo_glu et al., 2005).

In the present study, serum IGF-1 is significantly lower than healthy control group. Notably, liver cirrhosis, in which the hepatic tissue is irreversibly replaced by fibrosis, necrosis, and regenerating nodules, leads to the deterioration of normal liver function. Systematically, cirrhosis patients experience several clinical manifestations of their decreased metabolic liver function and subsequent IGF-I deficiency and growth hormone elevation (Abdel-Wahab et al., 2015).

We investigated the effects of zinc supplementation for 4 months on catch-up growth in infant and children with chronic cholestatic liver diseases. There was significant increase in serum zinc level and IGF-1. It has been associated with significant improvement in the height (length) $Z$-score and percentile. It was reported that

Table 4 Anthropometric measurements, serum zinc, and IGF 1 of the cholestatic patients before and after zinc supplementation

\begin{tabular}{|c|c|c|c|}
\hline$\underline{\text { Variables }}$ & Initial & After 4 months & $P$ value \\
\hline MUAC Z-score (median (IQR), [range]) & $-1.5(2),[-5.9: 0.9]$ & $1.5(1.3),[-3.7: 0.6]$ & $>0.05$ \\
\hline MUAC percentile (median (IQR), [range]) & $7(41),[0.00: 82]$ & $6(23),[0.00: 71]$ & $>0.05$ \\
\hline TSF Z-score (median (IQR), [range]) & $-2.45(1.8),[-7.7: 0.2]$ & $-2(2.6),[-5.09: 0.1]$ & $>0.05$ \\
\hline TSF percentile (median (IQR), [range]) & 1 (3), [0.00:58] & $2.5(21),[0.00: 55]$ & $>0.05$ \\
\hline Weight Z-score (median (IQR), [range]) & $-1.2(1.9),[-5.5: 6.3]$ & $-0.7(1.9),[-2.7: 94]$ & $>0.05$ \\
\hline Weight percentile (median (IQR), [range]) & $11.5(37),[-2.7: 97]$ & $22(53),[0.00: 88]$ & $>0.05$ \\
\hline Height (length) Z-score (median (IQR), [range]) & $-1.6(2.6),[-4.8: 41]$ & $-0.5(2.6),[-2.5: 16]$ & $0.01^{*}$ \\
\hline Height (length) percentile (median (IQR), [range]) & $4(31),[-0.23: 99]$ & $21(58),[-0.9: 100]$ & $0.01^{*}$ \\
\hline Serum Zn (mean \pm SD) $\mu \mathrm{g} / \mathrm{l}$ & $1252 \pm 557$ & $2223 \pm 1042$ & $0.001^{*}$ \\
\hline IGF-1 (median (IQR), [range]) ng/ml & 54 (118), [10:780] & 346 (370), [50:825] & $0.001^{*}$ \\
\hline
\end{tabular}

TSF tricuspid skin fold thickness, $m m$ millimeters, MUAC mid upper arm circumference, $\mathrm{cm}$ centimeter, $\mathrm{Zn}$ zinc, IGF-1 insulin-like growth factor 1 ${ }^{*} P<0.05$ is significant 
undernourished children with serum zinc concentrations of $<750 \mu \mathrm{g} / \mathrm{l}$ experienced significant increase in height, weight, weight-for-age, and BMI-for-age $Z$-scores after 12- and 24-week zinc supplementation when compared with the children with a serum zinc concentration of $\geq$ $750 \mu \mathrm{g} / \mathrm{l}$ (Chao et al., 2018). Zinc supplementation in infants and early childhood improves specific growth outcomes, with evidence for a potentially stronger effect after 2 years of age (Liu et al., 2018). Moreover, consumption of zinc ( $50 \mathrm{mg} /$ day for 2 months) improved the secretion of growth hormone in children aged 3.716.2 years. It has been postulated that zinc influence on increased bone formation may be via IGF-1, the growth factor produced mainly by the liver and, to a lesser extent, by non-hepatic tissues including bone. Once IGF-1 is secreted by osteoblasts in response to growth hormone and parathyroid hormone (Canalis et al., 1989), it recruits preosteoblasts to the bone-remodeling surface and increases the synthesis of bone collagen and matrix (Hershkovitz et al., 1999). Indeed, the relation between zinc supply and IGF-1 has been observed in children with short stature (Imamo_glu et al., 2005) and failure to thrive infants (Hershkovitz et al., 1999). Thus, we can speculate that the effect of zinc could be mediated by increasing IGF-1 (Himoto \& Masaki, 2018).

\section{Conclusions}

In our study, zinc supplements improved growth in infants and children with chronic cholestatic liver disease. Zinc supplementation should be part of the micronutrient intake of infants and children with chronic cholestatic liver disease.

\section{Abbreviations \\ ALK: Alkaline phosphatase; ALT: Alanine aminotransferase; AST: Aspartate aminotransferase; GGT: Glutamyltranspeptidase; IGF-1: Insulin growth factor 1; INR: International Normalized Ratio; IQR: Interquartile range; MUAC: Mid upper arm circumference; SD: Standard deviation; TSF: Tricuspid skin fold thickness}

\section{Acknowledgements \\ We would like to thank Nehal Elkoufy, Professor of Pediatrics, Pediatrics Hepatology Unit, Cairo University, for her guidance and advice during this work, and Mona Fahmy, Professor of Pediatrics, National Ophthalmology Institute, for her help in the statistics. We highly appreciate the unlimited excellent technical support and consultancies provided by the research team of Dr. Hanan Sayed Ibrahim, the head of the research group; Atomic Spectra; the central laboratories network; and the National Research Center. Without their support, the completion of the work would not have been possible.}

\section{Authors' contributions}

All authors participated in the development and implementation of the research plan and subsequently written it. All authors read and approved the final manuscript.

\section{Funding}

The National Research Center Grant supported the laboratory work. The funding source is not involved in the study design, collection, interpretation of data, or publication of this article.

\section{Availability of data and materials}

All data generated or analyzed during this study are included in this published article

\section{Ethics approval and consent to participate}

The institutional ethical committee (registration number 15152) approved the study protocol and carried out in compliance with the Declaration of Helsinki (2008). Informed consent was obtained from the parents and/or caregivers of all participants before the procedure, according to the guidelines of the ethical committee.

\section{Consent for publication}

We have approved the manuscript for submission to your journal hoping it will be accepted for publication.

\section{Competing interests}

The authors declare that they have no competing interests.

\section{Author details}

1Department of Pediatrics, National Research Center, El Buhouth St, Dokki, Cairo 12311, Egypt. ${ }^{2}$ Department of Clinical Pathology, National Research Center, Cairo, Egypt.

Received: 9 June 2019 Accepted: 16 July 2019

Published online: 26 July 2019

\section{References}

Abdel-Wahab R, Shehata S, Hassan M et al (2015) Type I insulin-like growth factor as a liver reserve assessment tool in hepatocellular carcinoma. Journal of Hepatocellular Carcinoma 2:131-142

Adulcikas J, Sonda S, Norouzi S, Sohal SS, Myers S (2019) Targeting the zinc transporter ZIP7 in the treatment of insulin resistance and type 2 diabetes. Nutrients 11:408. https://doi.org/10.3390/nu11020408

Bonefeld K, Møller S (2011) Insulin-like growth factor-I and the liver. Liver Int. 31(7):911-919

Canalis E, Centrella M, Burch W et al (1989) Insulin-like growth factor I mediates selective anabolic effects of parathyroid hormone in bone cultures. J Clin Invest 83:60-65

Chao HC, Chang YJ, Huang WL (2018) Cut-off serum zinc concentration affecting the appetite, growth, and nutrition status of undernourished children supplemented with zinc. Nutr clin pract 33:701-710. https://doi. org/10.1002/ncp.10079 Epub 2018 Mar 30

Ghali I, Salah N, Hussien F, Erfan M, El-Ruby M, Mazen I et al (2008) Egyptian growth curves for infants, children and adolescents. Published. In: Satorio A, Buckler JMH, Marazzi N (eds) Crecerenelmondo. Ferring Publisher, Italy, p 2008

Hershkovitz E, Printzman L, Segev Y et al (1999) Zinc supplementation increases the level of serum insulin-like growth factor-I but does not promote growth in infants with nonorganic failure to thrive. Horm Res 52:200-204

Himoto T, Masaki T (2018) Associations between zinc deficiency and metabolic abnormalities in patients with chronic liver disease. Nutrients. 10:88. https:// doi.org/10.3390/nu10010088

Holt RI, Jones JS, Baker AJ et al (1999) The effect of short stature, portal hypertension, and cholestasis on growth hormone resistance in children with liver disease. J Clin Endocrinol Metab. 84(9):3277-3282

Imamo_glu S, Bereket A, Turan S et al (2005) Effect of zinc supplementation on growth hormone secretion, IGF-I, IGFBP-3, somatomedin generation, alkaline phosphatase, osteocalcin and growth in prepubertal children with idiopathic short stature. J Pediatr Endocrinol Metab 18:69-74

Krebs N (2000) Overview of zinc absorption and excretion in the human gastrointestinal tract. J Nutr. 130:1374-1377

Lin CC, Huang JF, Tsai LY et al (2006) Selenium, iron,copper, and zinc levels and copper-to-zinc ratios in serum of patients at different stages of viral hepatic diseases. Biol Trace Elem Res 109:15-24

Lindenmayer GW, Stoltzfus RJ, Prendergast AJ (2013) Interactions between zinc deficiency and environmental enteropathy in developing countries. Adv Nutr 4:176-190

Liu E, Pimpin L, Shulkin M, Kranz S, Duggan CP, Mozaffarian D, Fawzi WW (2018) Age. Nutrients 10:377. https://doi.org/10.3390/nu10030377

Mohammad MK, Zhou Z, Cave M et al (2012) Zinc and liver disease. Nutr Clin Pract 27:8-2 
Monge MF, Barrado E, Vicente CA, Redondo del Río MP, Marugán de Miguelsanz JM (2019) Zinc nutritional status in patients with cystic fibrosis. Nutrients. https://doi.org/10.3390/nu11010150

Narkewicz MR, Krebs N, Karrer F et al (1999) Correction of hypozincemia following liver transplantation in children is associated with reduced urinary zinc loss. Hepatology 29:830-833

Ninh NX, Thissen JP, Collette L et al (1996) Zinc supplementation increases growth and circulating insulin-likegrowth factor I (IGF-I) in growth-retarded Vietnamese children. Am J ClinNutr 63:514-519

Ohlsson C, Mohan S, Sjögren K et al (2009) The role of liver-derived insulin-like growth factor-I. Endocr Rev. 30(5):494-535

Paul AA, Cole TJ, Ahmed EA, Whitehead RG (1998) The need for revised standards for skinfold thickness in infancy. Arch Dis Child. 78:354-358

Pereira TC, Saron ML, Carvalho WA et al (2011) Research on zinc blood levels and nutritional status in adolescents with autoimmune hepatitis. Arq Gastroenterol 48:62-65

Petry N, Olofin I, Boy E et al (2016) The effect of low dose iron and zinc intake on child. micronutrient status and development during the first 1000 days of life: a systematic review and meta-analysis. Nutrients 8:773. https://doi.org/10.3390/nu8120773

Prasad AS (2013) Discovery of human zinc deficiency: its impact on human health. Adv Nutr 4:176-190

Sandström B (1997) Bioavailability of zinc. Eur J ClinNutr 51 Suppl 1:S17-S19

Soldin SJ, Brugnara C, Hicks JM (1999) Pediatric reference ranges, 3rd edn. American Association for Clinical Chemistry, Washington, D.C

Sultan S, Irfan SM, Kakar J et al (2015) Effect of iron chelator desferrioxamine on serum zinc levels in patients with beta thalassemia major. Malays J Pathol 37:35-38

Tako E (2019) Updates on the linoleic acid: dihomo-p-linolenic acid ratio (LA: DGLA)- as an emerging biomarker of zinc status. Curr Dev Nutr. 13. https:/ doi.org/10.1093/cdn/nzz044.P24-019-19

Umusig-Quitain P, Gregorio GV (2010) High incidence of zinc deficiency among Filipino children with compensated and decompensated liver disease. J Gastroenterol Hepatol 25:387-390. https://doi.org/10.1111/ j.1440-1746.2009.06003.x

Wanzira H, Lazzerini M (2016) Oral zinc for treating diarrhea in children. Cochrane Database Syst Rev. (12):CD005436. https://doi.org/10.1 002/14651858.CD005436.pub5

World Health Organization (2004) Food and Agriculture Organization. Vitamin and mineral requirements in human nutrition, 2nd edn. World Health Organization, Geneva

\section{Publisher's Note}

Springer Nature remains neutral with regard to jurisdictional claims in published maps and institutional affiliations.

\section{Submit your manuscript to a SpringerOpen ${ }^{\circ}$ journal and benefit from:}

- Convenient online submission

- Rigorous peer review

- Open access: articles freely available online

- High visibility within the field

- Retaining the copyright to your article

Submit your next manuscript at $\boldsymbol{\nabla}$ springeropen.com 